\title{
O PROCESSO DE ESCUTA NA REDUÇÃO DE DANOS: CONTRIBUIÇÕES DE ROGERS E KIERKEGAARD
}

\author{
The Process of Listening in Harm Reduction: Rogers and Kierkegaard Contributions
}

El Proceso de Escucha en la Reducción de Daños: Contribuciones de Rogers y Kierkegaard

\author{
BReno Augusto da Costa \\ Thabata Castelo Branco Telles
}

\begin{abstract}
Resumo: A redução de danos é uma estratégia de manejo de comportamentos de alto risco, considerada humanizada e pragmática. Existem diversas convergências com o campo da Saúde Coletiva, especialmente por ser uma prática baseada no vínculo e na relação de horizontalidade entre o cuidador e a pessoa cuidada. O objetivo desse trabalho é discutir o processo de escuta na redução de danos, destacando possíveis contribuições de Rogers e Kierkegaard. Trata-se de um estudo teórico. Foram coletados textos sobre a prática de redução de danos, e as informações sobre o processo de escuta foram discutidas e refletidas a partir dos dois pensadores, com possível interlocução. Nesta perspectiva, o usuário é visto como protagonista no processo de cuidado. A escuta, a partir de atitudes de empatia e consideração positiva incondicional do redutor é fundamental, pois desvela sentidos. Conclui-se que, na redução de danos, a prática da escuta é fundamental no cuidado ao usuário, e o pensamento de Rogers e Kierkegaard fornecem subsídios para a compreensão dos mecanismos da escuta e fundamentação de uma escuta qualificada.

Palavras-chave: Redução de danos; Políticas públicas de saúde; Rogers; Kierkegaard; Escuta.

Abstract: The harm reduction is a strategy of management of high-risk behaviors and it is considered humanized and pragmatic. There are many convergence points with the Collective Health field, especially for its foundation in the rapport and horizontal nature of the relationship between health professional and patient. The aim of this work is to discuss the process of listening in harm reduction, highlighting Rogers's and Kierkegaard's contributions. This is a bibliographical research. Texts about the practice of harm reduction have been collected and the information about the process of listening was discussed through the perspectives of the two thinkers and their possible interlocution. From this viewpoint the user is considered as a main character in the process of care. The listening from attitudes of empathy and positive unconditional regard from the redactor is fundamental because it unveils meanings. The conclusion is that the listening is fundamental in the user existential project and Rogers's and Kierkegaard's thoughts provide subsidies to the comprehension of listening mechanisms and foundation to a qualified listening. Keywords: Harm reduction; Public health policy; Rogers; Kierkegaard; Listening.

Resumen: La reducción de daños es una estrategia de gestión de los comportamientos de alto riesgo considerada humana y pragmática. Hay muchas convergencias con el campo de la salud pública, sobre todo porque es una práctica basada en la relación y la relación horizontal entre el cuidador y la persona cuidada. El objetivo de este trabajo es discutir el proceso de escucha en la reducción de daños, poniendo de relieve las posibles contribuciones de Rogers y Kierkegaard. Este es un estudio teórico. Los textos sobre el tema y la información sobre el proceso de cuidado fueran recogidos y se debatidos al pensamiento de los dos pensadores y su posible interlocución. En esta perspectiva, el usuario es el protagonista en el proceso de atención. El escuchar desde actitudes empáticas y con consideración positiva incondicional es importante porque desvela sentidos. Se concluye que en la reducción de daños escuchar es clave en el proyecto existencial del usuario y el pensamiento de Kierkegaard y Rogers y proporcionan subsidios para la comprensión de los mecanismos de escucha y fundamentan una escucha cualificada. Palabras clave: Reduccíon de daños; Políticas públicas de salud; Rogers; Kierkegaard; Escucha.
\end{abstract}

\section{Introdução}

A redução de danos é uma estratégia que pode ser formulada na forma de políticas, programas e práticas para lidar com comportamentos de risco à saúde dos indivíduos. Desde sua sistematização, na Holanda, em 1982, a redução de danos vem sendo adotada como política pública em diversos contextos, notadamente na redução de consequências nocivas, associadas ao abuso de drogas. As pessoas que usam drogas, suas famílias e toda comunidade podem ser beneficiados com as práticas de redução de danos (Associação Brasileira de Redução de Da- nos, 2011; Marlatt, 1999; International Harm Reduction Association, 2010).

De acordo com Alan Marlatt (1999), os princípios da redução de danos estabelecem-na como uma alternativa aos modelos moral, criminal e biomédico de cuidado ao abuso de drogas e, embora ela reconheça a abstinência como meta ideal, aceita práticas que diminuam gradativamente os efeitos nocivos do abuso. Enquanto política pública, a redução de danos é considerada uma abordagem horizontal na relação de cuidado, uma vez que, na interação entre o profissional e a pessoa que usa drogas, não existe a premissa de que o primeiro tenha alguma 
vantagem ou superioridade sobre o segundo. É também considerada uma abordagem "de baixo para cima" na estruturação de programas, ou seja, o próprio usuário deve tomar a iniciativa na estruturação de estratégias para cuidar de sua saúde, que são assimiladas pelas instâncias políticas de gestão em saúde no desenvolvimento de programas; além disso, é uma política vantajosa, já que promove o acesso a serviços de baixa exigência e de baixo custo.

A International Harm Reduction Association (2010), maior comunidade de pesquisadores e trabalhadores em redução de danos, considerada uma referência na formulação de políticas e desenvolvimento de pesquisas, emitiu, em abril de 2010, uma posição oficial acerca do conceito de redução de danos. Neste documento, estão estabelecidos os princípios da redução de danos, salientando-se seu compromisso com a saúde pública e os direitos humanos. A redução de danos é dirigida aos riscos e efeitos nocivos de alguma prática, nesse sentido, devem ser levados em conta diversos aspectos do indivíduo em risco: idade, gênero e contexto social e cultural. Pragmática, ela tem o empenho de basear suas ações em evidências científicas, tornando-se uma forma eficaz e de baixo custo, em relação aos altos benefícios que promove. Suas ações devem ter caráter facilitador, e não coercitivo, sendo baseadas nas necessidades do indivíduo, o que implica em aceitar metas construídas pela própria pessoa que usa drogas, levando-se em conta diversas prioridades: a abstinência é uma meta desejável na redução de danos, porém, o cuidado imediato à saúde do indivíduo é prioritário. Respeito e tolerância devem ser observados, quando se relacionando com uma pessoa que usa drogas, além disso, o redutor deve evitar julgamentos morais e a estigmatização das pessoas.

De acordo com Petuco e Medeiros (s. n.) as principais contribuições da redução de danos para o cuidado aos usuários de álcool e outras drogas são: a não exigibilidade da abstinência para oferecer os cuidados; a promoção do direito de participação política dos indivíduos que usam drogas, no sentido do conhecimento das políticas públicas como um todo que afetam-no; e o trabalho de campo, que aborda o indivíduo a partir de seu próprio contexto.

No âmbito do Sistema Único de Saúde (SUS), podemos destacar diversas políticas públicas e portarias que fundamentam a prática da redução de danos no território brasileiro (Brasil, 2004; Brasil, 2005a; Brasil, 2005b; Brasil, 2012; Brasil, 2013). As primeiras práticas de redução de danos no Brasil, bem como a consolidação através de políticas públicas do SUS foram tematizadas por Petuco e Medeiros (s. n.). Tal como estabelecido pelas diretrizes do SUS, que os beneficiários desse sistema de saúde pública sejam denominados usuários, nesse trabalho, será adotado o termo usuário para a pessoa alvo da redução de danos, e o termo redutor será utilizado para denominar a pessoa que atua nesse sentido.

Tomando como referência o baixo custo e elevado benefício, bem como a concepção de homem adotada pela política de redução de danos (International Harm Reduction Association, 2010; Marlatt, 1999), existe uma alta compatibilidade e coerência entre esta proposta e as características do campo da saúde coletiva. Utiliza-se o termo saúde coletiva em detrimento de saúde pública, pois esta última se funda sobre um modelo biomédico e biologizante, enquanto a saúde coletiva é considerada um campo científico e de atuação com abertura para participação das ciências humanas. A psicologia, nesse contexto, contribui de forma a resgatar a problemática do cidadão-sujeito, contrapondo-se a qualquer posição biologizante e reducionista. O sujeito é visto como dinâmico e ativo na elaboração de sentidos para a realidade, sendo não previsível e não definido a priori (Galindo \& Francisco, 2013).

De acordo com Galindo e Francisco (2013), espera-se do psicólogo, atuando no campo da saúde coletiva, o cumprimento da função "de mediador, de facilitador de processos, cujo protagonismo é dos sujeitos envolvidos. No caso do trabalho em serviços públicos de saúde, a relação com os usuários merece atenção específica” (p. 515). As autoras se fundamentam em Merhy (2009) para buscar um "modelo tecnoassistencial centrado no usuário", o que implica no uso de ferramentas como o acolhimento, a atenção e o olhar. Em suma, tais ferramentas, ou disposições profissionais, são contempladas e possíveis através do processo de escuta.

A mera percepção dos sons e até mesmo a interpretação de tais sons como componentes de uma frase ou discurso provém da capacidade de ouvir. Basta não ter nenhum impedimento orgânico e, no caso do uso da linguagem falada, compreender a língua falada pelo locutor para ouvi-lo. No entanto, isso não garante a escuta do interlocutor. A palavra escutar tem origem no latim e significa ouvir com atenção ou estar atento para ouvir (Cunha, 1991). Nesse sentido, este trabalho se propõe a discutir o processo de escuta na prática da redução de danos, a partir das contribuições de Rogers e Kierkegaard.

\section{Método}

Trata-se de uma pesquisa bibliográfica. Lima e Mioto (2007) definem a pesquisa bibliográfica como um procedimento metodológico utilizado para alcançar a resolução de problemáticas apresentadas em pesquisas. É relevante nos estudos exploratórios e descritivos, uma vez que se aproxima do objeto de estudo a partir de fontes bibliográficas, permitindo um amplo acesso a informações e, além disso, permitindo a utilização de conhecimentos pulverizados em diferentes publicações. Baseando-se em Salvador (1986), as autoras citam que a pesquisa bibliográfica possui quatro fases: na primeira, a fase de elaboração do projeto de pesquisa, em que ocorre a escolha do assunto e a elaboração da problemática; na segunda fase, a investigação de soluções, a bibliografia é elencada, bem como 
as informações do material bibliográfico são exploradas; na análise explicativa das soluções, fase seguinte, ocorre a análise dos materiais elencados e o exame das afirmações e conhecimentos em questão; finalmente, a última fase é a síntese integradora, fase em que, segundo as autoras, são realizadas ações de "apreensão do problema, investigação rigorosa, visualização de soluções e sínteses" (p. 41). Dessa forma, a síntese integradora é o resultado da análise e reflexão rigorosa sobre a bibliografia selecionada. As autoras citam também a relevância do estabelecimento de critérios que delimitam o universo de materiais de estudo e da realização de diferentes modalidades de leitura aos textos selecionados.

Nesse trabalho, foi realizada uma revisão narrativa da literatura, visando elencar a definição, os princípios e as diretrizes da redução de danos. Em seguida, aprofundou-se na explicitação do processo de relação entre usuário e redutor, para o estabelecimento da problemática e, consequentemente, dos objetivos do estudo. Foi evidenciada a questão da escuta nessa relação. Em seguida realizou-se a leitura dos textos com vistas a discutir a problemática. Os textos são discutidos a partir do referencial teórico de Carl Rogers (1902-1987) e Søren Kierkegaard (1813-1855), visando estabelecer as possíveis contribuições desses autores.

\section{Rogers e a Abordagem Centrada na Pessoa}

A Abordagem Centrada na Pessoa (ou no Cliente ${ }^{1}$ ), de Rogers, tem destaque na história da Psicologia e em outros campos de saber, em diversos aspectos. Os trabalhos rogerianos foram pioneiros na sistematização da prática psicoterápica e, além disso, contribuíram para o reconhecimento e valorização do psicólogo em diversos meios; sua obra contribuiu em diversos campos, desde a clínica individual ou grupos, até a apropriação de sua teoria no contexto educacional (Almeida, 2012; Araújo \& Vieira, 2013; Miranda \& Cury, 2010; Moreira, 2010; Zerbetto \& Rodrigues, 1997).

No contexto clínico, desde o início, o aconselhamento na perspectiva centrada no cliente foi caracterizado por uma busca sistemática de evidências empíricas com o intuito de sustentar os seus postulados. Dessa forma, essa abordagem visava um cunho eminentemente científico e objetivo. Tal proposta levou Rogers e seus colaboradores a questionarem os fatores comuns aos terapeutas, capazes de atingir resultados positivos e promotores da mudança

\footnotetext{
A distinção entre Teoria/Terapia Centrada no Cliente e Abordagem Centrada na Pessoa se refere ao processo de desenvolvimento teórico-prático de Carl Rogers, sendo a segunda a definição a mais tardia, em que Rogers compreende e atua em sua proposta para além da clínica individual, intervindo em grupos de caráter educacional, de gestão, dentre outros. Portanto, entendemos que esta perspectiva está mais condizente com as discussões realizadas ao longo deste trabalho. Remetemos o leitor ao texto de Moreira (2010) para aprofundamentos nessa distinção.
}

terapêutica do indivíduo, muito embora oriundos de diferentes abordagens psicológicas.

Em decorrência do amadurecimento teórico, percebido ao longo da sua obra, Rogers (1957/1994) postula que os fundamentos ou condições necessários para a mudança terapêutica podem ser estabelecidas da seguinte forma: (1) é necessário o contato psicológico entre duas pessoas; (2) a primeira pessoa, considerada o cliente, deve estar em um estado de incongruência, vulnerabilidade ou ansiedade; (3) a segunda pessoa, o terapeuta, deve estar integrado na relação, ou seja, apresentar congruência; além disso, (4) deve manifestar consideração (ou aceitação $0^{2}$ ) positiva incondicional pelo cliente e (5) experienciar uma compreensão empática do esquema de referências do cliente; finalmente, (6) deve ocorrer uma comunicação da consideração positiva e incondicional, bem como da compreensão empática entre o terapeuta e o cliente (Scheefer, 1986; Schmidt, 2013; Trijsburg, Colijn, \& Holmes, 2007).

Rogers tece comentários relevantes acerca da escuta no contexto clínico. A escuta, na sua perspectiva, ocorre com a pessoa que se apresenta, atitude essa que é tomada em detrimento da produção de avaliações ou julgamentos sobre a pessoa. Dessa forma, as condições de consideração positiva incondicional, bem como a empatia, são colocadas em evidência, uma vez que fundamentam este processo (Rogers, 1961/2010). Além disso, Rogers (1980/1987) salienta a importância de, nas suas palavras, ouvir realmente as pessoas; acessando o sentido profundo do discurso do interlocutor. Rogers aponta que, para ouvir realmente, é preciso realizar uma escuta profunda, em que "as palavras, os pensamentos, a tonalidade dos sentimentos, o significado pessoal, até mesmo o significado que subjaz às intenções conscientes do interlocutor" (1980/1987, p. 8) são escutados. O autor aponta que, por trás de uma mensagem que parece pouco importante, pode haver gritos profundos que a pessoa, ao mesmo tempo, gostaria e não gostaria de comunicar, portanto é preciso acessar e entender esses significados.

Outro conceito relevante na abordagem centrada na pessoa é o de tendência atualizante, segundo o qual o ser humano teria uma tendência natural de realizar suas potencialidades ou atualizá-las. Segundo Scheeffer (1961), a concepção da abordagem centrada na pessoa estabelece que existe uma direção natural "no sentido de crescimento, ajustamento, socialização, independência, autonomia e saúde" (p. 44). A autora afirma que a tendência atualizante é a motivação primária do ser humano. Além disso, a pessoa "é capaz de usar sua racionalidade para atingir os objetivos adequados e satisfatórios ao seu organismo, a fim de preencher suas tendências atualizantes” (p. 45),

\footnotetext{
2 Os termos "consideração" e "aceitação" são ambos encontrados nos textos de Rogers, traduzidos para o português. No caso deste trabalho, optamos pela utilização do termo "consideração", por acharmos mais próximo à noção de "regard", palavra utilizada em inglês, idioma original dos escritos.
} 
nesse sentido, a busca pela saúde se configuraria como uma potencialidade inerente ao ser.

Telles, Boris e Moreira (2014) destacam a tendência atualizante como um fluxo constante rumo à realização das possibilidades do homem e que dirige o funcionamento de todas suas funções, favorecendo sua conservação e enriquecimento. Os autores discutiram como tal concepção tem sido abordada por terapeutas que atuam a partir da abordagem centrada na pessoa e destacam a unanimidade manifestada pelos participantes ao colocar a tendência atualizante como relevante na prática clínica, em consonância com as condições necessárias para a mudança terapêutica. Esta noção, juntamente com as condições facilitadoras, ou seja, a consideração positiva incondicional, empatia e congruência, exercidas pelo terapeuta, se apresentam como base para que a importância da escuta no processo de redução de danos seja discutida a partir pensamento de Rogers.

\section{Søren Kierkegaard e a Psicologia Existencial}

O filósofo dinamarquês Søren Kierkegaard (18131855) é considerado por muitos como o fundador do existencialismo; movimento filosófico e literário muito relevante no século XX, que encontra sua unidade em diversas premissas e posições, tais como a concepção da liberdade como atributo do ser, a morte ou finitude no seu horizonte, a angústia como vivência afetiva básica e a discussão em torno da falta de sentido da existência humana. Kierkegaard, especificamente, tem como pontos fortes de sua produção a teologia, a contestação do iluminismo e sua ênfase na racionalidade, bem como a crítica à exagerada sistematização da obra de Hegel (Reynolds, 2014).

A obra de Kierkegaard foi apropriada por diversos campos, além da filosofia e da teologia. Na psicologia e psiquiatria, diversos autores buscaram fundamentação no filósofo ou em outros pensadores influenciados por ele. O próprio Kierkegaard, através de seus pseudônimos, produziu obras cujas reflexões eram denominadas por ele como psicológicas (Kierkegaard, 1843/2009, 1844/2015).

A análise existencial é um esforço realizado no sentido de elaborar uma psicologia com proposições clínicas a partir da filosofia kierkegaardeana. Isso significa assumir a obra do filósofo plenamente, concebendo que ela contém elementos suficientes para essa empreitada. Tal esforço, em primeiro lugar, deve ser diferenciado da análise existencial proposta por Binswanger. Em seguida, é preciso buscar no próprio Kierkegaard considerações acerca da psicologia. Nesse sentido, tal proposta realiza uma crítica a toda psicologia que se baseie na fisiologia ou biologia, uma vez que a psicologia deveria ocupar-se da existência humana em suas expressões concretas de angústia e liberdade (Feijoo, Mattar, Feijoo, Lessa, \& Protasio, 2013; Feijoo \& Protasio, 2014).
A concepção de ser humano em Kierkegaard não pode ser reduzida a modelos previsíveis ou fechados. Uma vez que a pessoa é dotada da liberdade de escolha, ela é um poder-ser, um ser em construção, inacabado e que, muitas vezes, age de forma irracional e paradoxal. Existem referenciais através dos quais as escolhas são realizadas e, nesse sentido, Kierkegaard propõe os estádios (ou estágios, fases) de vida como norteadores das escolhas do ser (Mondin, 2014).

A partir da perspectiva da análise existencial, Feijoo (2014) aponta que o terapeuta "tenta acompanhar a possibilidade de que as transformações existenciais possam acontecer" (p. 180), isso devido à relevância da vivência da angústia, retomando a condição de indeterminação e construção do ser e provocando uma constante tensão existencial. Além disso, nesta perspectiva, o terapeuta tem uma posição contrária à psicologia comum, que estabelece modelos ideais de funcionamento, em que o psicólogo deveria guiar o paciente à cura. Na psicologia com base na obra kierkegaardeana, o terapeuta tem consciência de sua limitação no conhecimento do psiquismo e com relação a verdades absolutas sobre seu funcionamento, por isso, sua atuação volta-se para a existência do paciente, na sua concretude, acompanhando-o no processo de lida com as possibilidades e escolhas.

Tanto a perspectiva de Rogers como de Kierkegaard se propõem a descentralizar o papel do processo terapêutico no psicoterapeuta, situando o paciente como protagonista. Contudo, esta atuação é entendida de modos distintos, dadas as devidas diferenças epistemológicas. É sobre a articulação entre essas duas propostas que trataremos a seguir.

\section{Articulação Rogers/Kierkegaard}

Discutindo os mecanismos de atuação da postura de consideração positiva incondicional e da compreensão empática, torna-se relevante Kierkegaard (1988), filósofo cujo pensamento foi considerado similar ao de Rogers, pelo próprio fundador da Abordagem Centrada na Pessoa, e sendo tal relação abordada por diversos acadêmicos (Holanda, 2014; Scheefer, 1986; Schimidt, 2013). No livro "Enten-Eller" (traduzido como "Either, Or" para o inglês e "Ou, Ou" para o português) escrito por Kierkegaard e publicado originalmente em 1843 ele nos traz:

Eu tenho apenas um amigo, e ele é o eco. Por que ele é meu amigo? Porque eu amo minha tristeza e o eco não quer tirá-la de mim. Eu tenho um único confidente, e ele é o silêncio da noite. Por que ele é meu confidente? Por que ele se mantém silencioso. (p. 33) ${ }^{3}$

\footnotetext{
Trecho original: "I have only one friend, and that is echo. Why is it my friend? Because I love my sorrow and echo does not take it away from me. I have only one confidant, and that is the silence of night. Why is it my confidant? Because it remains silent"
} 
O trabalho do terapeuta ou, no caso deste trabalho, do redutor de danos, quando apresenta a compreensão empática e, além disso, quando a comunica ao usuário, ou cliente, essa experiência de compreensão, é um trabalho que consiste naturalmente em ecoar aquilo que o usuário vivencia, enquanto experiência interior. Isso significa uma expressão genuína daquilo que o próprio usuário trouxe, sem colocar e nem tirar nada da experiência; significa abrir-se ao usuário, entrando em contato com o que ele é e, ao mesmo tempo, faz ele próprio se presenciar, tomando contato consigo. Retornando novamente à citação, o único confidente do Autor A (pseudônimo usado por Kierkegaard para escrever essa passagem) é a noite, pois ela se mantém silenciosa. Nesse sentido, se mantém em atitude de suspensão de todos valores usados para julgar ou emitir uma opinião própria, em conflito com - no caso da redução de danos - a do usuário. Isso significa uma posição clara de abertura para quem manifesta respeito pela expressão do outro como ela é, sem considerar aquela expressão a partir de vivências e referências próprias.

O próprio Rogers, na obra Tornar-se Pessoa (1961/2010), cita diversas vezes Kierkegaard. No início do décimo capítulo, ele aponta que seu contato inicial com o pensamento do filósofo dinamarquês se deu graças à recomendação insistente de alguns colegas acadêmicos do curso de Teologia, que viram diversas correspondências entre os trabalhos de Rogers e os filósofos considerados existencialistas: Martin Buber e Søren Kierkegaard.

Rogers (1961/2010) relata que, em determinada ocasião, foi convidado a participar de uma reunião de estudos, em que ele deveria apresentar a perspectiva centrada na pessoa no âmbito da aprendizagem. Na preparação para tal evento, Rogers optou pela imersão na leitura de Kierkegaard e afirmou que "o esforço honesto deste autor para chamar as coisas pelo seu nome" (p. 315) influenciou-o fortemente. Em seguida, ele afirma que "um conhecimento autodescoberto, essa verdade que foi pessoalmente apropriada e assimilada na experiência, não pode ser comunicada diretamente a outra pessoa" (p. 318), destacando, dessa forma, o papel da experiência própria na aprendizagem em geral. Em seguida, Rogers destaca a similaridade dessa conclusão com as de Kierkegaard, no entanto, não aponta exatamente quais os fundamentos para essa compreensão. Concebemos que a conclusão de Rogers pode ser articulada com a comunicação indireta de Kierkegaard, abordada por Feijoo et al. (2013, p. 46-50).

Feijoo et al. (2013) abordam a da comunicação indireta em Kierkegaard, afirmando que tal método de comunicação foi usado pelo pensador dinamarquês, inicialmente com intuitos religiosos, porém, de uma maneira geral, o propósito era resgatar o indivíduo em sua singularidade, livrando-o do impessoal e da multidão. De acordo com Scheeffer (1986), a correspondência entre o pensamento de Kierkegaard e Rogers manifesta-se principalmente na busca de autenticidade como o objetivo da vida plena que, segundo a autora, é visada no processo de acolhimento centrado no cliente. Feijoo et al (2013) destacam, no seu projeto de uma psicologia kierkegaardeana, que existem formas diferentes de desespero, inclusive o desespero de não ser si-próprio em que "o eu se desespera para se tornar algo diferente do que de fato se é” (p. 45). Assim, uma série de vivências afetivas pertenceriam ao caminho percorrido para alcançar a vida plena, tais como o desespero, que culminam, de certa forma, na incongruência. A incongruência em Rogers, de acordo com Scheeffer (1986), "desenvolve-se em termos de desacordo ou dissociação entre o autoconceito do indivíduo e as experiências do seu organismo" (p. 48). Esta sensação de incongruência seria o ponto de partida para o processo de mudança; tal questão encontra-se convergente tanto na perspectiva de Rogers, como de Kierkegaard, pois o filósofo dinamarquês tematiza o desespero de se tornar diferente daquilo que de fato se é, ou seja, essa reflexão pode ser articulada com o pensamento de Rogers acerca da incongruência. Assim, destacamos que esta sensação de incongruência seria o ponto de partida para o processo de mudança em ambos os autores.

\section{Processo de Escuta na Redução de Danos: contri- buições de Rogers e Kierkegaard}

Os princípios basilares da redução de danos estruturam-na enquanto uma abordagem considerada humana e pragmática, devido à relação estabelecida entre o redutor e o usuário, bem como de acordo com as metas e prioridades elencadas no programa desenvolvido no processo (International Harm Reduction Association, 2010; Marlatt, 1999). Marlatt (1999) propõe o pragmatismo da redução de danos como sendo paralelo à hierarquia das necessidades humanas segundo Maslow, isso implica na postulação da relevância de se trabalhar primeiro com as necessidades mais urgentes e básicas para a sobrevivência do indivíduo para, em seguida, buscar satisfazer os níveis de necessidades considerados mais elevados, como as necessidades psicológicas, sociais e as espirituais. Por outro lado, o autor coloca a ênfase da redução de danos no estabelecimento de uma parceria entre o usuário e o redutor, na qual o usuário é o principal responsável na definição das suas necessidades ou desenvolvimento dos serviços e do programa de cuidado à saúde, como sendo correspondente à abordagem centrada no cliente de Rogers.

Marlatt (1999) propôs a existência de uma correspondência entre a Abordagem Centrada na Pessoa e a prática de redução de danos, especialmente no âmbito da relação de cuidado. Porém, para realizar essa articulação, é preciso repensar a Abordagem Centrada na Pessoa em um contexto clínico clássico e o contexto da redução de danos. 
Como assumido anteriormente, a relação de cuidado na prática da redução de danos se dá entre o redutor e o usuário, dessa forma, podemos alterar o termo cliente, comum na abordagem de Rogers, por usuário (do SUS), bem como, terapeuta por redutor. A transposição referente ao setting clínico tradicional deve atentar às particularidades dos locais aonde ocorrem as ações de redução de danos, considerando-se a raridade do uso do consultório para a realização de atendimentos individuais. Segundo Marlatt (1999) a redução de danos, por ser uma abordagem de baixa exigência, se dispõe a encontrar o usuário aonde quer que ele esteja, em seus próprios termos. Assim, a redução de danos ocorre na própria comunidade, ou no lugar em que vive o usuário. Além disso, é preciso adaptação, por parte do psicólogo, para desenvolver ações pautadas nos princípios do SUS e a apropriação do perfil de profissional exigido. Por outro lado, deve ocorrer a problematização de sua atuação, com vistas a pensar e oferecer serviços alternativos, de acordo com as necessidades da população (Dimenstein, 1998). Feito isso, cumpre elaborar a forma como se dá o cuidado e a escuta na prática de redução de danos.

A relação entre o redutor e o usuário é uma relação genuína entre duas pessoas. Porém não é uma relação ordinária, do cotidiano; trata-se de uma relação de cuidado. Nesse sentido, será realizada a tentativa de defender a posição da prática de redução de danos como uma prática de therapéia em seu sentido primordial.

É preciso, antes disso, tecer algumas considerações em torno do cuidado. A essência do cuidar pode ser apreendida através do antigo mito de cura, expresso em Prado \& Caldas (2013). O ser humano, considerado um filho da Terra (Tellus) e do Céu (Júpiter), teria sua unidade no cuidado. O homem pertenceria ao cuidado enquanto vivesse, portanto, o cuidado seria inerente à vida do homem na terra e sua condição nesta (Fernandes, 2011). Cuidado, dessa forma, é associado à vida é às condições necessárias para a manutenção dela.

Na Grécia Antiga, havia majoritariamente dois grupos de pessoas empenhadas no cuidado à saúde da sociedade: os terapeutès e os iatrikós. Em comum entre ambos os grupos, havia o cuidado da saúde do corpo e da alma das pessoas, porém a arte fundamentadora das especificidades da atuação de cada um era essencialmente diferente. Os terapeutès eram praticantes da therapéia; arte de cuidar do próprio ser, enquanto os iatrikós praticavam a iatriké, arte de cuidar do próprio corpo. Uma distinção clara entre as duas artes era o fato do terapeutès cuidar do corpo e da alma através da alma, ou seja, esse cuidado se dava através da perspectiva da mediação do diálogo, pois a fala seria o modo de expressão da alma; além disso, a therapéia era considerada superior, pois sua atuação ia além da remissão de sintomas, uma vez que tinha ação preventiva e prospectiva. O iatrikós cuidava do corpo e da alma através do corpo, ou seja, empregava recursos capazes de cuidar do corpo e seus sintomas manifestados ali (Holanda, 2011).
Ao longo dos séculos, até chegar à nossa sociedade atual, tal distinção das duas artes perdeu seu rigor, embora ainda haja certa manutenção no cerne das ideias dessas práticas. Podemos observar uma clara diferenciação entre a atuação do psicoterapeuta e do psiquiatra. Tradicionalmente, o psicoterapeuta cuidaria do corpo e da alma através da alma, ou seja, oferece um cuidado através do diálogo, expressão da alma ou "psiquismo". Já o psiquiatra cuidaria do corpo e da alma através do corpo, ou seja, cuida de seus pacientes através de medicamentos e insumos modificadores das funções orgânicas e, assim, ocorrem alterações psíquicas ou das funções consideradas da alma.

O redutor de danos cuida do próprio ser do usuário, uma vez que permite emergir do próprio usuário as necessidades mais proeminentes e as possíveis intervenções ou projetos a serem desenvolvidos, tanto a curto, quando médio ou longo prazo, quando possível. O redutor age de forma a provocar um espaço de diálogo, em que o usuário propõe a sua própria via de cura ou caminho do cuidado, sendo assim, existe a prática da therapéia, cujo cuidado tem um caráter mais preventivo e de se voltar ao futuro e suas possibilidades.

Na concepção de Kierkegaard, o homem é sempre um poder ser, sendo construído, modificado e transformado de acordo com as possibilidades apresentadas a ele. Dentre suas possibilidades, o homem deve realizar escolhas e arcar com as consequências destas, portanto ele é o responsável por esse processo de se construir, modificar e transformar (Mondin, 2014).

Um dos princípios da redução de danos, enquanto política pública, como já citado anteriormente, é a sua concepção de relação horizontal entre usuário e redutor, e a elaboração de "baixo para cima", ou seja, partindo dos próprios usuários em direção aos formuladores de políticas públicas. Historicamente, após a sistematização dessa proposta, o comprometimento principal com a condução e tomada de iniciativas no desenvolvimento de serviços e programas vinham sempre por parte dos usuários. Isso significa que os programas individuais ganhavam força através de associações e cada vez mais subiam hierarquicamente, até se tornarem políticas públicas mais amplas, um movimento inverso ao das políticas construídas de cima para baixo, ou seja, aquelas promovidas pelos formuladores de políticas de drogas, sem o devido contato e articulação com os usuários para a construção dessa política. Tal princípio foi estabelecido após a constatação do fato dos próprios usuários de drogas terem maior conhecimento acerca dos seus problemas do que qualquer outra pessoa e, dessa forma, eles próprios seriam capazes de propor iniciativas de combate à deterioração da sua saúde (Marlatt, 1999).

Uma vez admitida a capacidade do próprio usuário em reconhecer as melhores ações para sua saúde, é necessário assumir o processo de cuidado entre o redutor e o usuário como demandante de uma escuta por parte 
do redutor. O programa de redução de danos, seja individual, seja instituído através de políticas mais amplas, só poderá ser construído e executado através de uma escuta cuidadosa por parte do redutor, uma escuta qualificada. Nesse sentido, torna-se relevante salientar a distinção entre ouvir e escutar.

Como já citado anteriormente, a mera percepção dos sons e até mesmo a interpretação de tais sons, como componentes de uma frase ou discurso, provém da capacidade de ouvir. A palavra escutar significa ouvir com atenção ou estar atento para ouvir (Cunha, 1991). A escuta é a capacidade das pessoas de acessarem o sentido formulado. De acordo com Amatuzzi (2011), para escutar, é preciso reencontrar escondida sob a linguagem empírica e suas diferentes manifestações, a palavra viva, em que o sentido se formula e se torna disponível para outras operações.

A linguagem torna comum algo próprio de cada ser, o pensamento. O pensamento expressa o mundo vivido pela pessoa. Esse processo de transformação de pensamento em palavra é uma tradução em palavras daquilo que essencialmente é uma não-palavra. Escutar uma pessoa, chamado também por Mauro Amatuzzi de ouvir bem, ou por Carl Rogers de ouvir profundamente, é um processo através do qual se entra em contato com essa pessoa e o mundo dela, constituído "de tudo que é recebido pela pessoa, mas também de tudo que foi construído por sua história pessoal, pela história de suas emoções, sentimentos, reações, e pelo seu momento presente em que nos fala" (Amatuzzi, 2011, p. 70).

Maynart, Albuquerque, Breda e Jorge (2014) abordam a escuta qualificada a partir da perspectiva dos usuários de um Centro de Atenção Psicossocial (CAPS). Segundo os autores, a escuta qualificada envolve relações do tipo diálogo, vínculo, acolhimento e permite compreender o sofrimento a partir da própria pessoa, da expressão da pessoa, além disso, atenta para as demandas dela, que é escutada e considerada uma ferramenta facilitadora e transformadora. Na concepção dos participantes da pesquisa, a escuta qualificada ocorre quando há, dentre outros, compreensão e respeito ao indivíduo. Aqui, pode-se aludir um paralelo com a consideração positiva incondicional e a empatia. A empatia, expressa pelo profissional, pode gerar a sensação de ser compreendido no usuário, uma vez habitando no mundo de uma pessoa e expressando isso, naturalmente ela vai se sentir compreendida, e a consideração positiva incondicional vai promover esse sentimento de respeito, de poder expressar-se como se é.

Dessa forma, a escuta pode ser estabelecida como uma postura de colocar-se aberto para acolher os sons e os sentidos emergentes na relação com o outro (Lima, Yehia, \& Morato, 2009), e não meramente a percepção de um discurso. Rogers (1961/2010) salienta a relevância de escutar com a pessoa, em um processo de horizontalidade da relação entre redutor e usuário, tal como estabele- ce um dos princípios da redução de danos. Esse processo de construção em conjunto implica se centrar no próprio usuário no seu programa de cuidado.

A partir das obras de Kierkegaard e sua articulação com a Psicologia, Protasio (2014) propõe que cabe à escuta (denominada pela autora como escuta privilegiada) fundamentar uma prática na qual o homem deve entrar em contato com as suas angústias e, assim, vislumbrar a si mesmo e as suas possibilidades, desse modo, ele será capaz de formar e transformar a si mesmo. Esse movimento de vislumbrar a si próprio pode ser provocado pela comunicação da vivência empática, realizada pelo terapeuta ou pelo redutor de danos. O Autor A, do livro "Either/Or" (Kierkegaard, 1843/1988), valida essa afirmação ao colocar o eco como seu único amigo, como citado anteriormente. Nessa situação, longe de desejar remover a tristeza do Autor A, o eco apenas reflete o conteúdo verbal recebido.

Portanto, do processo de escuta emerge o sentido, sendo desvelado pelo próprio usuário junto com o redutor, e assim se constrói uma trama de desenvolvimento da própria pessoa, que é capaz de assumir um caminho de cuidar de si e do seu próprio ser. Inicialmente, o discurso do usuário, como o discurso de qualquer pessoa, vai expressar níveis mais baixos das necessidades hierárquicas, para depois alcançar outras dimensões. Em suma, ao entrar em contato consigo próprio, ao se ver e ser aceito como se é, o usuário tem condições de se transformar, uma vez que as possibilidades emergem do seu discurso com sentido e com disponibilidade para se efetivarem.

De acordo com a tendência atualizante, concebida por Rogers, haverá sempre uma destinação à saúde, ao bem estar, à realização das potencialidades do ser (Scheeffer, 1986; Telles, Moreira \& Boris, 2014). O usuário desvelaria, assim, os sentidos, de forma a construir ou buscar esses recursos.

Dessa forma, o terapeuta, ou redutor, conforme o caso, não se implica de forma indiferente na relação de cuidado, ele deve se posicionar de modo a expressar uma série de atitudes características do processo de cuidado psicológico e outras características e atitudes peculiares à prática de redução de danos. Há um compromisso de fazer o usuário se reconhecer, ou seja, o redutor deve tentar habitar o mundo do usuário e auxiliar a mostrar a ele suas escolhas, responsabilidades e vivências e, assim, o usuário, em sua singularidade, será capaz de assumir posições sobre a sua vida (Feijoo et al., 2013). Tal posicionamento, de certa forma, possui convergências com as proposições de Rogers acerca das condições fundamentais para a promoção da mudança. Schimidt (2013) afirma que "a compreensão empática pede a suspensão do julgamento sobre o outro e a integridade daquele que compreende, remetendo a um modo de ser que interessa às relações psicoterápicas, mas não exclusivamente a elas” (p. 133). O movimento de compreensão empática desloca o poder para a pessoa, e não ao terapeuta. Na redução de danos, 
este ponto é fundamental, pois implica em uma atitude de empoderamento do usuário.

\section{Considerações finais}

A redução de danos é uma modalidade de cuidado que pode ser elaborada na forma de política pública, estratégia de atenção à saúde ou um programa pontual e específico de lida com comportamentos de alto risco à saúde e bem-estar. Tomando como base uma concepção de cuidado que se refira à vida em sua cotidianidade e manejo das questões que nela se manifestam, podemos conceber a prática de redução de danos como uma forma de cuidar da pessoa, favorecendo o desvelamento de sentidos a partir do diálogo entre usuário e redutor. Esse cuidado, nesse caso, ocorre de pessoa para pessoa, em uma relação de horizontalidade, implicando no respeito às decisões do usuário e aceitação do contexto cultural em que este se insere. As políticas públicas de redução de danos empregam recursos de forma pragmática e realista, ou seja, ajustada com a realidade e as possibilidades de ganhos efetivos em impactos positivos na saúde das pessoas e da sociedade. Como estratégia de atenção à saúde, a redução de danos se propõe a cuidar da pessoa de uma forma acolhedora e respeitosa, levando em conta suas escolhas, de forma a criar um vínculo adequado de cuidado.

A pessoa alvo da redução de danos é vista como um ser inserido em determinada situação social e cultural, isso implica numa marcante discussão da diversidade de valores e significados morais; dessa forma, as drogas são consideradas como elementos neutros, e os efeitos nocivos do seu abuso é que são tomados como o objeto de intervenção da redução de danos. A intervenção, por sua vez, é um processo cuja relação do redutor com o usuário compõe o cerne. A escuta, partindo das demandas do próprio usuário e tendo como horizonte as possibilidades elaboradas pelo próprio usuário, ocupa lugar de destaque nesse processo.

O processo de escuta na redução de danos é de relevância singular. Por ser uma atividade relacional entre o redutor e o usuário, em suma, entre duas pessoas, podemos dizer que a escuta segue um curso de aproximação de dois seres, em que um expressa ao outro sentidos através da sua fala. No caminho da escuta, o sentido é desvelado como uma forma de compreensão de si próprio e do próprio modo de ser, bem como uma forma de fomento de transformação e mudança. Na prática da redução de danos, em casos em que já estão manifestos agravos à saúde, é possível conceber a emergência da busca de comportamentos consideráveis saudáveis, como também uma melhor relação com as questões sociais, econômicas, culturais, dentre outras, que permeiam o cotidiano do usuário. É relevante ressaltar que, uma vez que há o desvelamento de sentidos, no diálogo entre redutor e usuário, existe uma compreensão voltada ao futuro do ser, fundamentada pelas necessidades hierárquicas mais urgentes e simples, em consonância com o seu modo de vida. Na prática da redução de danos, em casos em que já estão manifestos agravos à saúde, é possível conceber a existência de uma primazia pela busca de comportamentos saudáveis ou modos de ser consideráveis saudáveis, uma vez que existe uma destinação para o futuro do ser, fundamentada pelas necessidades hierárquicas mais urgentes e simples.

As contribuições de Rogers e Kierkegaard na prática da escuta na redução de danos se manifestam mais fortemente de duas formas: na compreensão dos mecanismos de atuação da escuta do redutor e na fundamentação de uma escuta qualificada. A compreensão dos mecanismos ocorre graças à elucidação dos sentidos desvelados pela escuta e a tendência atualizante do ser que se mantém como horizonte, ou seja, há uma propensão a atitudes promotoras de crescimento e realização das próprias possibilidades. A fundamentação da escuta com atitudes de empatia e consideração positiva incondicional promove a transformação do usuário e o empoderamento deste no seu processo de cuidado de si.

A redução de danos é muito utilizada nos casos em que há danos à saúde já consumados, ou seja, na assistência à saúde; porém, pode ser estendida, através de uma escuta com condições que foram discutidas acima, à promoção de saúde ou prevenção de agravos à saúde e também à reabilitação, no estabelecimento de projetos existenciais.

\section{Referências}

Almeida, L. R. (2012). Das Relações Entre Educação e Psicologia na Perspectiva de uma Educadora. Psicologia Escolar e Educacional, 16(2), p. 341-348.

Amatuzzi, M. M. (2011). Por uma Psicologia Humana. Campinas: Alínea.

Araújo, E. S., \& Vieira, V. M. (Janeiro/Junho de 2013). Práticas Docentes na Saúde: Contribuições para uma reflexão a partir de Carl Rogers. Revista Semestral da Associação Brasileira de Psicologia Escolar e Educacional, 17(1), p. 97/104.

Brasil. Ministério da Saúde. Secretaria de Atenção à Saúde. Departamento de Ações Programáticas Estratégicas (2004). Álcool e Redução de Danos: uma abordagem inovadora para países em transição. Brasília: Ministério da Saúde.

Brasil. Ministério da Saúde. Secretaria de Atenção à Saúde. DAPE. Coordenação Geral de Saúde Mental (2005a). Reforma Psiquiátrica e Política de Saúde Mental no Brasil. Documento apresentado à Conferência Regional de Reforma dos Serviços de Saúde Mental: 15 anos depois de Caracas. OPAS. Brasília.

Brasil. Ministério da Saúde (2005b). Portaria $n^{\circ} 1.028$, De $1^{\circ}$ De julho de 2005. Determina que as ações que visam à redução de danos sociais e à saúde, decorrentes do uso de produtos, 
substâncias ou drogas que causem dependência, sejam reguladas por esta Portaria. Brasília: Presidência da República.

Brasil. Ministério da Saúde (2012). Portaria no 122, de 25 de janeiro de 2012. Define as diretrizes de organização e financiamento das Equipes de Consultório na Rua. Brasília: Presidência da República.

Brasil, Ministério da Saúde (2013). Guia de Saúde Mental. Atendimento e intervenção com usuário de álcool e outras drogas. Brasília: Ministério da Saúde.

Cunha, A. G. (1991). Dicionário Etimológico Nova Fronteira da Língua Portuguesa. Rio de Janeiro: Nova Fronteira.

Dimenstein, M. D. (1998). O psicólogo nas Unidades Básicas de Saúde: desafios para a formação e atuação profissionais. Estudos de Psicologia, 3(1), p. 53-81.

Feijoo, A. M., \& Protasio, M. M. (2014). Angústia e Repetição: da Filosofia à Psicologia. Rio de Janeiro: Edições IFEN.

Feijoo, A. M., Mattar, C. M., Feijoo, E. L., Lessa, M. B., \& Protasio, M. M. (2013). O Pensamento de Kierkegaard e a Clínica Psicológica. Rio de Janeiro: IFEN.

Fernandes, M. A. (2011). Do Cuidado da Fenomenologia à Fenomenologia do Cuidado. Em A. J. Peixoto, \& A. F. Holanda, Fenomenologia do Cuidado e do Cuidar: Perspectivas multidisciplinares (p. 132). Curitiba: Juruá.

Galindo, W. C., \& Francisco, A. L. (2013). Psicologia e Saúde Coletiva: Notas para debate. Em C. L. Barreto, H. T. Morato, \& M. T. Caldas, Prática Psicológica na Perspectiva Fenomenológica (p. 505-522). Curitiba: Juruá.

Holanda, A. F. (2011). Fenomenologia do "Cuidado": Reflexões para um olhar sobre o binômio saúde-doença. In: A. J. Peixoto, \& A. F. Holanda, Fenomenologia do Cuidado e do Cuidar: Perspectivas multidisciplinares (p. 67-83). Curitiba: Juruá.

Holanda, A. F. (2014). Fenomenologia e Humanismo: Reflexões necessárias. Curitiba: Juruá.

International Harm Reduction Association. (2010). Harm Reduction International. Fonte: International Harm Reduction Association: <http://www.ihra.net/files/2010/06/01/Briefing_what_is_HR_Portuguese.pdf $>$.

Kierkegaard, S. (1843/1988). Either/Or. Part I. (E. H. Howard V. Hong, Ed.) Princeton, NJ: Princeton University Press.

Kierkegaard, S. (1843/2009). Repetition and Philosophical Crumbs. Oxford: Oxford University Press.

Kierkegaard, S. (1844/2015). O Conceito de Angústia: Uma simples reflexão psicológico-demonstrativa direcionada ao problema do pecado hereditário. Petrópolis: Vozes.

Lima, D. F., Yehia, G. Y., \& Morato, H. T. (2009). Os "Sentidos" da Escuta Fenomenológico-Existencial. Em H. T. Morato, C. L. Barreto, \& A. P. Nunes, Aconselhamento Psicológico numa Perspectiva Fenomenológica Existencial: uma introdução (p. 406). Rio de Janeiro: Guanabara Koogan.

Lima, T. C. S. \& Mioto, R. C. T. (2007). Procedimentos Metodológicos na Construção do Conhecimento Científico: a pesquisa bibliográfica. Revista Katálysis, 10. p 37-45.
Marlatt, A. (1999). Redução de Danos: Estratégias para lidar com comportamentos de alto risco. (D. Bueno, Trad.) Porto Alegre: Artmed.

Maynart, W., Albuquerque, M., Breda, M. \& Jorge, J. (2014). A Escuta Qualificada e o Acolhimento na Atenção Psicossocial. Acta Paulista de Enfermagem, 27(4), p. 300-304.

Merhy, E. E. (2009). Enfrentar a lógica do trabalho em saúde: um ensaio sobre a micropolítica do trabalho vivo no ato, no cuidado. In: Carvalho, S. R.; Ferigato, S. B.; Barros, M. E. (Orgs.) (2009). Conexões: Saúde Coletiva e Políticas de Subjetividade. São Paulo: Aderaldo \& Rothschild

Miranda, R. \& Cury, V. (2010). Dançar o adolescer: estudo fenomenológico com um grupo de dança de rua em uma escola. Paidéia (Ribeirão Preto), 20(47), p. 391-400.

Mondin, B. (2014). Curso de Filosofia: os filósofos do Ocidente (12 ${ }^{\text {a }}$ Reimpressão ed., Vol. 3). São Paulo: Paulus.

Moreira, V. (2010). Revisitando as Fases da Abordagem Centrada na Pessoa. Estudos Psicológicos, 27(4), p. 537-544.

Petuco, D.R.S \& Medeiros, R.G. (s. n) Saúde Mental, álcool e outras drogas. Contribuição à IV Conferência Nacional de Saúde Mental - Intersetorial. Recuperado em: 24 de setembro, 2016, de: <http://www.redehumanizasus.net/sites/default/ files/ad_iv_conf.pdf $>$.

Prado, R. A., \& Caldas, M. T. (2013). Atitude Fenomenológica Existencial e Cuidado na Ação Clínica. Em C. L. Barreto, H. T. Morato, \& M. T. Caldas, Prática Psicológica na Perspectiva Fenomenológica (p. 560). Curitiba: Juruá.

Protasio, M. M. (2014). Angústia e Repetição na Psicologia Clínica. Em A. M. Feijoo, \& M. M. Protasio, Angústia e Pretição: da filosofia à psicologia (p. 196). Rio de Janeiro: IFEN.

Reynolds, J. (2014). Existencialismo. Petrópolis: Vozes.

Rogers, C. (1994). As condições necessárias e suficientes para a mudança terapêutica da personalidade. In J. Wood et al. (Orgs.) Abordagem centrada na pessoa (p. 155-177). Vitória: Editora Fundação Ceciliano Abel de Almeida.

Rogers, C. (1961/2010). Tornar-se Pessoa. São Paulo: Martins Fontes.

Rogers, C. (1980/1987). Um Jeito de Ser. São Paulo : EPU.

Salvador, A. (1986). Métodos e Técnicas de Pesquisa Bibliográfica. Porto Alegre: Sulina.

Scheefer, R. (1986). Teorias de Aconselhamento. São Paulo: Atlas.

Schmidt, M. L. (2013). Apontamentos Críticos à Teoria da Mudança de Carl Rogers. Em C. L. Barreto, H. T. Morato, \& M. T. Caldas, Prática Psicológica na Perspectiva Fenomenológica (p. 560). Curitiba: Juruá.

Telles, T.C.B.; Moreira, V. \& Boris, J. (2014). O conceito de tendência atualizante na prática clínica contemporânea de psicoterapeutas humanistas. Revista da Abordagem Gestáltica, 20(1), p. 13-20. 
Trijsburg, R., Colijn, S., \& Holmes, J. (2007). Integração em Psicoterapia. Em G. Gabbard, J. Beck, \& J. Holmes, Compêndio de Psicoterapia de Oxford (p. 712). Porto Alegre: Artmed.

Zerbetto, S. R. \& Rodrigues, A. R. (1997). Relacionamento não Diretivo do Enfermeiro com Paciente em Processo de Ressocialização. Revista Latino-Americana de Enfermagem, 5(Especial), p. 77-83.

Breno Augusto da Costa - Psicólogo pela Universidade Federal do Triângulo Mineiro (UFTM). Membro-fundador da Liga Acadêmica de Fenomenologia Existencial (LAFEN/UFTM). Endereço: Av. Alexandre Barbosa, 1454, Mercês. CEP: 38.060-200. Uberaba/MG. E-mail: brenobac@gmail.com

Thabata Castelo Branco Telles - Doutoranda em Psicologia (FFCLRPUSP/FAPESP), com ênfase em lutas e fenomenologia. Possui graduação em Psicologia (UNIFOR/CNPq) e Mestrado em Psicologia (UNIFOR/ FUNCAP), este último com foco na fenomenologia de M. Merleau-Ponty e em psicopatologia cultural. Foi Professora Substituta da Universidade Federal do Triângulo Mineiro (UFTM), no Departamento de Psicologia (2014/2015). E-mail: thabata@gmail.com

Recebido em 11.05.2016

Primeira Decisão Editorial em 23.09.2016

Aceito em 08.12.2016 